\title{
Endothelin-1 is a useful biomarker for early detection of bronchiolitis obliterans in lung transplant recipients
}

\author{
Mohamed Salama, MD, ${ }^{\mathrm{a}, \mathrm{b}}$ Peter Jaksch, MD, ${ }^{\mathrm{a}}$ Olena Andrukhova, PhD, ${ }^{\mathrm{b}}$ Shahrokh Taghavi, MD, ${ }^{\mathrm{a}}$ \\ Walter Klepetko, $\mathrm{MD},{ }^{\mathrm{a}}$ and Seyedhossein Aharinejad, $\mathrm{MD}, \mathrm{PhD}^{\mathrm{a}, \mathrm{b}}$
}

\begin{abstract}
Objectives: Bronchiolitis obliterans (BO) is a severe complication limiting long-term survival after lung transplantation. To date, no cure exists for BO, and the mechanisms leading to $\mathrm{BO}$ are not well understood. Endothelin-1 (ET-1) is a potent mitogenic and profibrotic peptide produced by pulmonary vascular endothelial cells that play a role in the pathophysiology of lung allograft dysfunction. Whether ET-1 could predict BO syndrome (BOS) development is unknown.
\end{abstract}

\begin{abstract}
Methods: Transbronchial biopsy specimens and serum and bronchoalveolar lavage were obtained from 30 lung transplantation patients with and 30 without BOS at 3 points. The serum and bronchoalveolar lavage ET- 1 concentrations were measured by enzyme-linked immunosorbent assay, and the ET-1 mRNA expression in the transbronchial biopsy specimens was examined using real-time polymerase chain reaction.
\end{abstract}

Results: The pretransplant ET-1 serum concentrations were greater in the patients with BOS $(P=.02)$; and ET-1 mRNA was significantly upregulated in the lung grafts of those with versus those without BOS at 3 and 12 months after transplant $(P=.01)$. At 3 and 12 months after transplantation, the ET-1 concentrations were significantly elevated in the serum $(P<.01$ and $P<.0001$, respectively $)$ and bronchoalveolar lavage $(P<.01$ and $P=.02$, respectively) of patients with compared with those without BOS. On logistic regression analysis, the pretransplant and 3-month post-transplant serum ET-1 level predicted for BOS (odds ratio, 1.01; 95\% confidence interval, 1.004-1.025; $P<.007$; odds ratio, $2.9 ; 95 \%$ confidence interval, $1.01-8.52 ; P<.001)$. The serum ET-1 level at 12 months was diagnostic for BOS (odds ratio, 3.9; 95\% confidence interval, 1.42-10.80; $P=.008)$.

Conclusions: Elevated serum ET-1 concentrations were predictive of BOS, and the assessment of circulating ET-1 might be beneficial in diagnosing and monitoring BO. (J Thorac Cardiovasc Surg 2010;140:1422-7)

Bronchiolitis obliterans syndrome (BOS) remains the major cause of late graft loss in lung transplant recipients. ${ }^{1}$ BOS affects $18 \%$ to $57 \%$ of lung allograft recipients within the first 5 years after transplantation. It also accounts for more than $30 \%$ of all deaths after the third post-transplant year. ${ }^{1,2}$ Histologically, BOS is characterized by obliterative bronchiolitis and, physiologically, by deterioration of pulmonary function and a decrease in the forced expiratory volume in 1 second $\left.\left(\mathrm{FEV}_{1}\right)\right)^{3,4}$ Although the $\mathrm{FEV}_{1}$ is the main diagnostic tool of BOS, transbronchial biopsy (TBB) remains the reference standard. However, TBB is invasive and difficult to perform repeatedly in patients with impaired

Department of Cardiothoracic Surgery, ${ }^{\mathrm{a}}$ and Laboratory for Cardiovascular Research, Center of Anatomy and Cell Biology, ${ }^{\mathrm{b}}$ Medical University of Vienna, Vienna, Austria.

This study was supported by Grant 12988 from the Austrian National Bank to S. Taghavi and S. Aharinejad.

Disclosures: None.

Received for publication May 4, 2010; revisions received Aug 3, 2010; accepted for publication Aug 15, 2010.

Address for reprints: Seyedhossein Aharinejad, MD, PhD, Department of Cardiothoracic Surgery, Medical University of Vienna, Waehringer Guertel 18-20, Vienna A1090 Austria (E-mail: seyedhossein.aharinejad@meduniwien.ac.at).

$0022-5223 / \$ 36.00$

Copyright (C) 2010 by The American Association for Thoracic Surgery doi:10.1016/j.jtcvs.2010.08.046 pulmonary function. More importantly, obtaining tissue by TBB that will allow a conclusive diagnosis of BO might be problematic. Also, false-negative histologic results can occur despite the declining pulmonary function.

The pathogenesis of BOS remains unclear, although repeated injury to the allograft by ischemia reperfusion, acute rejection, inflammation, alloreactivity directed toward HLA antigens and infections, particularly cytomegalovirus (CMV) infection, have been thought to contribute to BOS development. ${ }^{3,5}$ These assaults are followed by responsive neutrophil and lymphocyte infiltration of the allograft, with secondary activation of various cytokines and chemokines, which contribute to inflammatory cell infiltration and BOS progression. ${ }^{6}$ Endothelin (ET)-1 is one of the main cytokines and is expressed in the endothelium, smooth muscle cells, airway epithelium, and alveolar macrophages of the lung. ${ }^{7}$ Evidence has suggested that ET-1 is involved in many pulmonary diseases, including pulmonary fibrosis ${ }^{8}$ and acute respiratory distress syndrome. ${ }^{9}$ Moreover, studies using animal models have indicated that ET-1 might have an effect on the development of BO..$^{10,11}$

We have previously reported that ET-1 mediates increased vascular permeability and edema formation in lung grafts before reperfusion and primary graft dysfunction, 


\author{
Abbreviations and Acronyms \\ $\mathrm{BAL}=$ bronchoalveolar lavage \\ $\mathrm{BO}=$ bronchiolitis obliterans \\ $\mathrm{BOS}=$ bronchiolitis obliterans syndrome \\ $\mathrm{CI}=$ confidence interval \\ $\mathrm{CMV}=$ cytomegalovirus \\ ET-1 = endothelin-1 \\ $\mathrm{FEV}_{1}=$ forced expiratory volume in 1 second \\ $\mathrm{OR}=$ odds ratio \\ $\mathrm{PCR}=$ polymerase chain reaction \\ $\mathrm{TBB}=$ transbronchial biopsy
}

a common risk factor for BOS. ${ }^{12,13}$ Others have shown that antagonizing ET-1 in experimental lung transplantation prevents fibrous airway obliteration. ${ }^{14}$ In the present study, we addressed the utility of ET-1 in the prediction of BOS development in lung transplant recipients.

\section{PATIENTS AND METHODS \\ Patients}

The ethics committee of the Medical University of Vienna approved the present study. A total of 60 patients who had undergone lung transplantation between 2006 and 2009 and who have given informed consent to participate were enrolled. The demographic data and the most relevant characteristics of the patients are listed in Table 1. The serum samples were obtained shortly before transfer to the operating room. Moreover, TBB, serum, and bronchoalveolar lavage (BAL) samples were obtained at 3 and 12 months after transplantation during routine clinical follow-up.

All samples were coded and snap frozen. All patients were routinely followed up weekly in the first 3 weeks, monthly during the first year, and every 2 months for the second year after transplantation, or when clinically indicated. The surveillance protocol involved the patients' history, physical status, pulmonary function tests, blood tests, and bronchoscopy with BAL and TBB. All TBB and BAL samples were examined histologically by an independent pathologist.

\section{BOS Diagnosis and Classification}

The average of the 2 greatest pulmonary function measurements obtained at least 3 weeks apart during the post-transplant course was used to establish the baseline $\mathrm{FEV}_{1}$ and the forced expiratory flow at $25 \%$ to $75 \%$ of the vital capacity. BOS was then classified, according to the International Society for Heart and Lung Transplantation Society guidelines ${ }^{15}$ : stage $0, \mathrm{FEV}_{1}$ of $90 \%$ or more and forced expiratory flow at $25 \%$ to $75 \%$ of the vital capacity of $75 \%$ or more; stage $0-p, F_{1}$ of $81 \%$ to $89 \%$; stage $1, \mathrm{FEV}_{1}$ of $66 \%$ to $80 \%$; stage $2, \mathrm{FEV}_{1} 51 \%$ to $65 \%$; and stage 3 , $\mathrm{FEV}_{1}$ of less than $50 \%$. Other causes of a decline in the $\mathrm{FEV}_{1}$ were excluded by bronchoscopy with TBB and BAL and high-resolution computed tomography.

\section{Diagnosis and Treatment of Rejection and Infection}

Rejection was diagnosed histologically in the TBB samples and graded according to the International Society for Heart and Lung Transplantation scoring. Rejection was suspected clinically if patients had new radiographic pulmonary opacification and deterioration of the blood gases and pulmonary function without evidence of infection despite a TBB score of $\mathrm{A} 0$ or B0 to B1. These patients underwent steroid pulse therapy at $1 \mathrm{~g} /$ d for 3 days. If the patient was resistant to the steroid pulse therapy, muromonab-CD3 (OKT-3) was administered at $5 \mathrm{mg} / \mathrm{d}$ for 7 days. An episode of infection was defined clinically and approved using microbiologic, serologic, or histologic tests. CMV screening was performed by measurement of CMV serology (quantitative polymerase chain reaction [PCR]) and the detection of CMV early antigen in blood, urine, throat smear, and BAL. Bacterial and fungal cultures and PCR for toxoplasmosis and pneumocystis carinii were performed in each BAL. The TBB specimens were also histologically screened for CMV, pneumocystis carinii, toxoplasmosis, and bacterial or invasive fungal infection. Colonization was considered present if the BAL microbiology was positive without histologic or clinical evidence of infection. ${ }^{16}$

\section{Immunosuppression}

The immunosuppression protocol has been previously described. ${ }^{16}$ In brief, the patients received $1 \mathrm{~g}$ methylprednisolone intraoperatively, followed by $125 \mathrm{mg}$ at 8,16 , and 24 hours postoperatively. Thereafter, prednisolone was administered at $1 \mathrm{mg} / \mathrm{kg} / \mathrm{d}$ and tapered to $0.25 \mathrm{mg} / \mathrm{kg}$ within 3 months. All patients received rabbit-antithymocyte globulin (Thymoglobulin; Sero-Merieux, Lyon, France) $2.5 \mathrm{mg} / \mathrm{kg}$ intravenously for the first 4 postoperative days. Mycophenolate mofetil (CellCept; Hoffmann-La Roche, Basel, Switzerland) at $3 \mathrm{~g} / \mathrm{d}$ was given intravenously on the first postoperative day and then orally. Cyclosporine A (target level $350 \mathrm{ng} /$ $\mathrm{mL}$ ) or tacrolimus (target level $15 \pm 3 \mathrm{ng} / \mathrm{mL}$ ) was administered intravenously immediately after surgery and subsequently switched to oral administration.

\section{BOS Management}

The treatment of patients with BOS was initiated after the diagnosis of BOS from the pulmonary function test results when other causes of FEV decline had been excluded. Recipients with BOS received steroid bolus therapy at $1000 \mathrm{mg} / \mathrm{d}$ for 3 days. Next, the steroid was reduced to $1 \mathrm{mg} / \mathrm{kg}$ within 2 weeks. The recipients then underwent pulmonary function testing and bronchoscopy every 2 weeks until stabilization. In the case of BOS resistance, the immunosuppression regimen was changed as follows. Cyclosporine A was switched to tacrolimus with a target serum level of $18 \pm 2 \mathrm{ng} / \mathrm{mL}$, depending on kidney function. If the switch in immunosuppression was not effective, the steroid treatment was repeated. If this therapy failed, the patient received clarithromycin, rabbit antithymocyte globulin (Thymoglobulin) or muromonab-CD3 (OKT-3), as described in the "Diagnosis and treatment of rejection and infection" section.

\section{Enzyme-Linked Immunosorbent Assay}

An enzyme-linked immunosorbent assay for ET-1 (TiterZyme EIA, Catalogue No. 900-020; Assay Designs, Minneapolis, Minn) was performed according to the manufacturer's protocol. Standard or serum samples were added to each polyclonal ET-1 antibody precoated well and incubated at $4{ }^{\circ} \mathrm{C}$ overnight. The substrate reaction was quantified spectrophotometrically using a 96-well, automated microplate reader (Anthos, Salzburg, Austria) at $450 \mathrm{~nm}$. The cross reactivity of the assay with other endothelin isotypes was less than $0.1 .^{13}$

\section{Quantitative Real-Time Reverse Transcriptase PCR}

Total RNA was isolated from the TBB specimens with TRIzol (Invitrogen, Carlsbad, Calif), using MagNA Lyser (Roche, Mannheim, Germany). Real-time reverse transcriptase PCR was performed on a LightCycler instrument (Roche), as previously described. ${ }^{13}$ The primer sequences were sense/antisense: ET-1: 5'-GGAAAAGACTGTTCCAAGC-3'/5'-GGTTG TGGGTCACATAACG- $3^{\prime}$; and $\beta_{2}$-microglobulin: $5^{\prime}$-GATGAGTATGCCT GCCGTGTG- $3^{\prime} / 5^{\prime}$-CAATCCAAATGCGGCATCT- ${ }^{\prime}$. The expression of the target gene was determined by relative quantification (ie, normalization to the expression of the housekeeping gene, $\beta_{2}$-microglobulin ${ }^{13}$ ) and 
TABLE 1. Demographic and clinical characteristics of study patients

\begin{tabular}{|c|c|c|c|c|c|}
\hline \multirow[b]{2}{*}{ Characteristic } & \multirow[b]{2}{*}{ All patients $(n=60)$} & \multicolumn{4}{|c|}{ BOS } \\
\hline & & Grade $0(n=30)$ & Grade $1(n=10)$ & Grade $2(n=10)$ & Grade $3(n=10)$ \\
\hline Mean age (y) & $50 \pm 15$ & $49 \pm 16$ & $54 \pm 14$ & $53 \pm 14$ & $51 \pm 14$ \\
\hline Male gender (n) & $32(53 \%)$ & $16(53 \%)$ & $5(50 \%)$ & $5(50 \%)$ & $6(60 \%)$ \\
\hline \multicolumn{6}{|l|}{ LTX type } \\
\hline SLTX & 14 & 5 & 3 & 4 & 2 \\
\hline DLTX & 46 & 25 & 7 & 6 & 8 \\
\hline Mean interval after LTX (mo) & 12 & 12 & 12 & 12 & 12 \\
\hline Mean ischemic time (min) & $320 \pm 41$ & $318 \pm 42$ & $315 \pm 23$ & $340 \pm 71$ & $341 \pm 63$ \\
\hline Mechanical ventilation (d) & 4 & 4 & 5 & 4 & $11 *$ \\
\hline ICU stay $(d)$ & 7 & 7 & 6 & 4 & $12^{*}$ \\
\hline $\mathrm{FEV}_{1}$ at discharge & $54 \pm 24$ & $58 \pm 24$ & $50 \pm 22$ & $48 \pm 19$ & $34 \pm 26^{*}$ \\
\hline PGD (n) & $25(43 \%)$ & $9(30 \%)$ & $5(50 \%) \dagger$ & $5(50 \%) \dagger$ & $6(60 \%) \dagger$ \\
\hline Bacterial infection & 12 & 8 & 0 & 3 & 1 \\
\hline Fungal infection & 11 & 7 & 2 & 1 & 1 \\
\hline CMV infection & 7 & 3 & 1 & 1 & 2 \\
\hline \multicolumn{6}{|l|}{ Immunosuppression } \\
\hline Tacrolimus/CyA & $44 / 16$ & $23 / 7$ & $7 / 3$ & $8 / 2$ & $6 / 4$ \\
\hline \multicolumn{6}{|l|}{ AR } \\
\hline A0 & 42 & $27(90 \%)$ & $7(70 \%)$ & $5(50 \%)$ & $3(30 \%) \ddagger$ \\
\hline A1 & 14 & $2(7 \%)$ & $3(30 \%)$ & $5(50 \%) \ddagger$ & $4(40 \%) \ddagger$ \\
\hline $\mathrm{A} 2$ & 2 & $1(3 \%)$ & 0 & 0 & $1(10 \%) \ddagger$ \\
\hline A3 & 2 & 0 & 0 & 0 & $2(20 \%) \ddagger$ \\
\hline B0 & 10 & $8(27 \%)$ & 0 & $1(10 \%)$ & $1(10 \%) \ddagger$ \\
\hline B1 & 34 & $19(63 \%)$ & $8(80 \%)$ & $3(30 \%)$ & $4(40 \%)$ \\
\hline $\mathrm{B} 2$ & 7 & $2(7 \%)$ & $1(10 \%)$ & $2(20 \%) \ddagger$ & $2(20 \%) \ddagger$ \\
\hline B3 & 9 & $1(3 \%)$ & $1(10 \%) \ddagger$ & $4(40 \%) \ddagger$ & $3(30 \%) \ddagger$ \\
\hline Incidence of $A R / y$ & $1.6 \pm 2.6$ & $0.3 \pm 0.4$ & $1.3 \pm 1.2$ & $4.5 \pm 4.2 \ddagger$ & $4.8 \pm 3.7 \ddagger$ \\
\hline Temporal pattern of AR (wk) & $2.7 \pm 2.4$ & $1 \pm 1.3$ & $2.6 \pm 2.1$ & $3.4 \pm 1.7 \ddagger$ & $5.5 \pm 2.5 \ddagger$ \\
\hline
\end{tabular}

$B O S$, Bronchiolitis obliterans syndrome; $L T X$, lung transplantation; $S L T X$, single LTX; $D L T X$, double LTX; ICU, intensive care unit; $F E V_{l}$, forced expiratory volume in $1 \mathrm{~s} ; P G D$, primary graft dysfunction; $C M V$, cytomegalovirus; $C y A$, cyclosporine $\mathrm{A} ; A R$, acute rejection. ${ }^{*} P=.02, \uparrow P=.04, \underset{\dagger}{\dagger} P<.001$ versus BOS grade 0 .

expressed as the relative expression levels. The average value of the 3 PCR measurements was used for data analysis.

\section{Statistical Analysis}

All parameters were compared between the patient groups using the $\chi^{2}$ test and analysis of variance (1-way analysis of variance; Tukey's post hoc test) according to the scale of the variable (categorical or continuous). The associations between the serum and BAL ET-1 and the acute rejection episodes were analyzed using Spearman's correlation coefficient. Repeated measures-analysis of variance was used to compare the repeated ET-1 measurements at the 3 follow-up points. Multiple logistic regression analysis was used to evaluate the confounder-adjusted effects of serum ET-1 to predict BOS, including all variables that were significant on univariate logistic regression analyses at $P=.05$. All statistical analyses were performed using Statistical Analysis Systems for Windows, version 9.1.3, and the Enterprise Guide, version 4.1 (SAS Institute, Inc, Cary, NC). Statistical -significance was set at $P<.05$. The results are expressed as the mean \pm standard deviation.

\section{RESULTS}

\section{Patient Clinical Characteristics}

In our study cohort, 10 patients had BOS grade 3,10 had BOS grade 2, 10 had BOS grade 1, and 30 had no BOS (grade 0) at 12 months after transplantation. The $\mathrm{FEV}_{1}$ at discharge from the hospital was significantly lower in the patients with BOS grade 3 than in those without BOS (grade $0)(P=.02$; Table 1$)$. The patients with BOS grade 3 required longer mechanical ventilation $(P=.02)$ and intensive care unit stay $(P=.02)$ than those with grade 0 . Moreover, the patients with BOS grade 2 and 3 had significantly more acute rejection episodes than the patients without BOS $(P<.001$; Table 1$)$. Moreover, the presence of BOS grade 2 and 3 was associated with a significantly temporal pattern of acute rejection episodes compared with BOS grade 0 and $1(P<.001$; Table 1$)$. Of note, BOS (grades 1 to 3$)$ was significantly associated with primary graft dysfunction after lung transplantation $(P=.04$; Table 1$)$. However, the frequency of CMV, bacterial, and fungal infections was not significantly different between those with and without BOS.

\section{Pretransplant Serum ET-1 Predicts BOS Development}

The pretransplant serum ET-1 levels were significantly greater in patients who developed BOS grade 1 to 3 $(P=.02$; Figure 1). However, no significant differences were found when the BOS grades were compared 
Pre-transplant serum ET-1

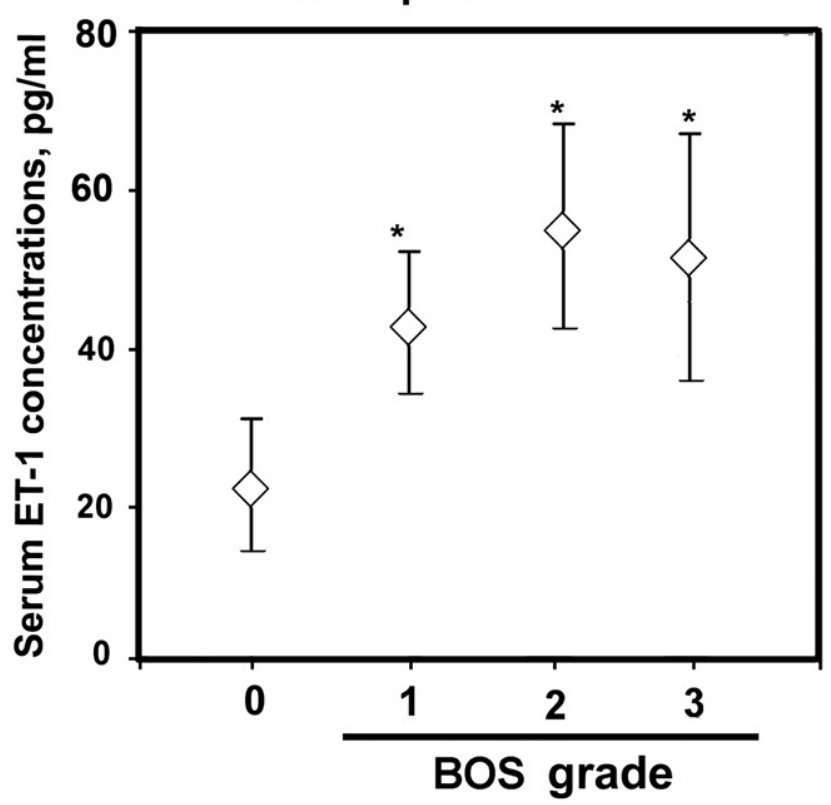

FIGURE 1. Pretransplant endothelin-1 (ET-1) serum concentrations were elevated in patients who developed bronchiolitis obliterans syndrome $(B O S)$. Pretransplant serum ET-1 levels were significantly increased in BOS grade 1 to 3 versus no BOS, although no significant differences were found in ET-1 serum levels when BOS grades were compared. $* P=.02$.

$(P=.21)$. Logistic regression analysis revealed that the pretransplant serum ET-1 level predicted BOS development (odds ratio [OR], 1.01; 95\% confidence interval [CI], 1.004-1.025; $P<.007$; Table 2). Recipient age, graft ischemic time, duration of mechanical ventilation, intensive care unit stay, $\mathrm{FEV}_{1}$ at discharge from the hospital did not predict for BOS (Table 2).

TABLE 2. Logistic regression analysis

\begin{tabular}{lcccc}
\hline \multicolumn{1}{c}{ Variable } & $\begin{array}{c}\text { Univariate } \\
\text { OR }(\mathbf{9 5} \% \mathbf{C I})\end{array}$ & $\begin{array}{c}\boldsymbol{P} \\
\text { value }\end{array}$ & $\begin{array}{c}\text { Adjusted } \\
\text { OR }(\mathbf{9 5} \% \mathbf{C I})\end{array}$ & $\begin{array}{c}\boldsymbol{P} \\
\text { value }\end{array}$ \\
\hline Pretransplant & $1.01(1.004-1.025)$ & .007 & - & - \\
$\quad$ serum ET-1 & & & & \\
Serum ET-1 at 3 mo & $3.1(1.21-9.92)$ & .001 & $2.9(1.01-8.52)$ & .001 \\
Serum ET-1 at 12 mo & $3.9(1.42-10.80)$ & .008 & $3.5(1.31-9.71)$ & .007 \\
AR & & & & \\
$\quad$ Grade A & $6.8(2.86-16.01)$ & .001 & $5.1(1.99-12.94)$ & .001 \\
$\quad$ Grade B & $4.1(2.28-7.54)$ & .001 & $3.4(1.82-6.72)$ & .001 \\
Age & $1.01(0.99-1.03)$ & .35 & & \\
Gender & $0.96(0.48-1.94)$ & .96 & & \\
Mechanical & $1.02(0.93-1.11)$ & .71 & & \\
$\quad$ ventilation & & & & \\
ICU stay & $0.99(0.92-1.08)$ & .94 & & \\
FEV ${ }_{1}$ at discharge & $0.89(0.73-1.11)$ & .30 & & \\
\hline$O R$ Odi
\end{tabular}

$O R$, Odds ratio; $C I$, confidence interval; $E T-1$, endothelin-1; other abbreviations as in Table 1 .

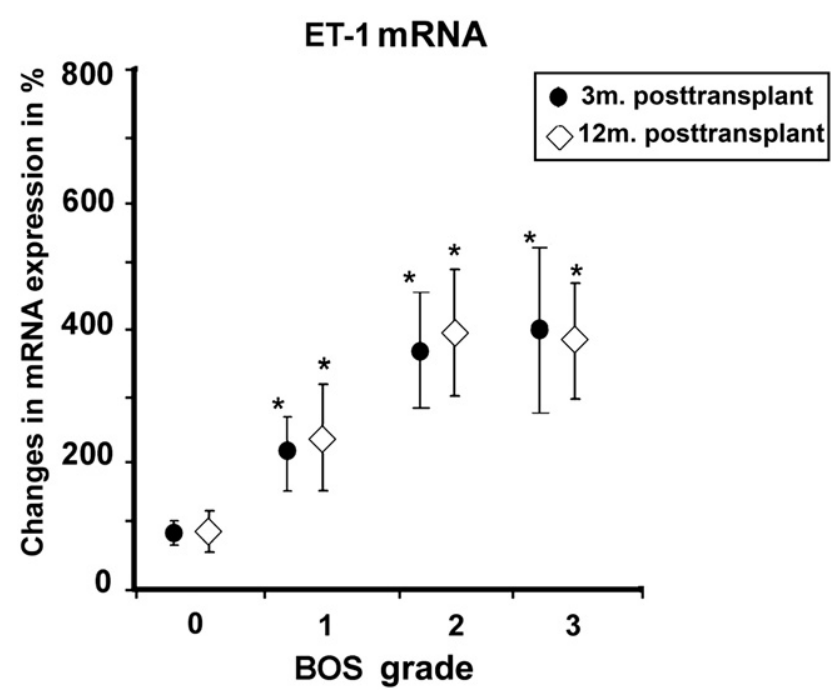

FIGURE 2. Endothelin-1 (ET-1) mRNA expression levels were elevated in lung tissue of patients with bronchiolitis obliterans syndrome (BOS). ET-1 pulmonary tissue mRNA expression at 3 and 12 months $(m$.) after transplant was resignificantly increased in BOS grades 1 to 3 versus without BOS, although no significant differences were found in ET-1 mRNA expression levels when BOS grades were compared. $* P=.01$.

\section{Elevated Post-Transplant Serum ET-1 Predicts BOS Development}

The ET-1 mRNA expression levels in the TBB specimens from patients with BOS (grade 1-3) were significantly greater than the expression levels from the TBB specimens of those without BOS at 3 and 12 months after transplantation $(P<.01$; Figure 2$)$. Moreover, the BAL ET-1 concentrations were significantly greater in the patients with BOS grade 2 or 3 than in those without BOS at 3 and 12 months after transplantation $(P<.01$ and $P=.02$, respectively; Figure 3,A). However, no significant differences were seen in the BAL ET- 1 concentrations when patients with BOS grade 1 were compared with those without BOS (Figure 3, $A$ ).

The serum ET-1 concentrations were significantly elevated in those with BOS grade 1 to 3 compared with those in the patients without BOS at 3 and 12 months after transplantation $(P<.01$ and $P<.001$, respectively; Figure $3, B)$. Also, no significant differences were found in the serum ET1 concentrations when patients with BOS grades 1 to 3 were compared (Figure 3, B). Moreover, no significant difference was found when the repeated ET-1 measurements at 3 and 12 months after transplantation were compared. However, the pretransplant serum ET-1 level was significantly greater than the ET- 1 concentrations at 3 and 12 months after transplantation in all patients $(P<.001)$.

The serum and BAL ET- 1 concentrations correlated significantly with each other in the study cohort $\left(\mathrm{r}_{\mathrm{s}}=0.63\right.$; $P<.01$ at 3 months and $\mathrm{r}_{\mathrm{s}}=0.72 ; P<.002$ at 12 months after transplantation). Moreover, serum ET-1 correlated 

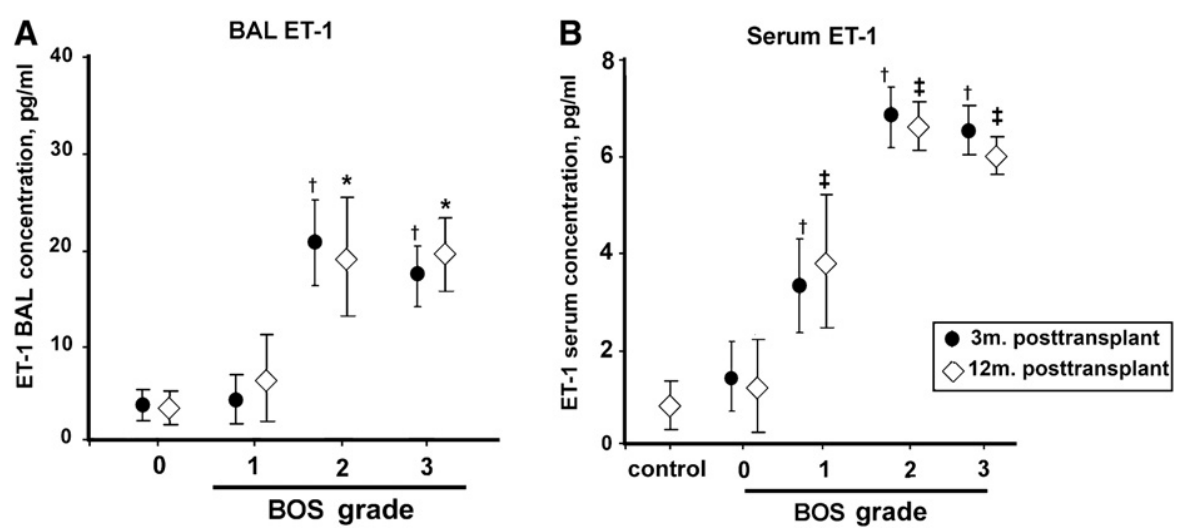

FIGURE 3. Endothelin-1 (ET-1) bronchoalveolar lavage $(B A L)$ and serum concentrations were elevated in patients with bronchiolitis obliterans syndrome $(B O S)$. (A) BAL ET-1 concentrations at 3 and 12 months $(m$.) after transplant were significantly increased in patients with BOS grades 2 and 3 but not grade 1 compared with those without BOS. (B) Serum ET-1 concentrations at 3 and 12 months were significantly elevated in those with BOS grade 1 to 3 compared with those in patients without BOS and healthy controls. $* P=.02, \dagger P<.01, \ddagger P<.001$.

significantly with the frequency of previous acute allograft rejection episodes: classification $\mathrm{A}\left(\mathrm{r}_{\mathrm{s}}=0.21 ; P=.024\right)$ and $\mathrm{B}\left(\mathrm{r}_{\mathrm{s}}=0.46 ; P<.0001\right)$. However, no difference was seen in the serum ET-1 levels among the study patients regarding their history of infection or type of immunosuppression.

Logistic regression analysis indicated that serum ET-1 at 3 months after transplantation predicts for BOS (OR, 2.9; 95\% CI, 1.01-8.52; $P<.001$; Table 2). Moreover, the serum ET-1 level measured after BOS development diagnosed BOS grade 1 to 3 as opposed to no BOS (OR, 3.9; 95\% CI, $1.42-10.80 ; P=.008$; Table 2$)$. In addition, logistic regression analysis showed that patients with repeated acute rejection episodes were at a greater risk of developing BOS: grade A (OR, 5.1; 95\% CI, 1.99-12.94; $P<.001)$ and grade B (OR, 3.4; 95\% CI, 1.82-6.72; $P<.001$; Table 2).

\section{DISCUSSION}

Although the etiology of BOS is not clearly understood, the existing evidence of the role of small airway inflammation and acute rejection in $\mathrm{BOS}^{5}$ strongly suggests that the cellular and humoral storm directed to the allograft is crucial in BOS. Several growth factors and cytokines, including ET-1, have been suggested to be involved in BOS pathogenesis. ${ }^{16-18}$ ET-1 possesses potent fibrogenic, vasoactive, and inflammatory properties that enable it to contribute to airway remodeling. In addition, ET-1 is thought to be involved in several inflammatory airway diseases such as asthma, bronchiectasis, and idiopathic lung fibrosis. ${ }^{8,9}$ Accordingly, experimental models have shown that ET-1 might be associated with $\mathrm{BO} .{ }^{11}$ Furthermore, an earlier work reported that ET-1 production in response to lung allograft injury starts early in donors and might influence the development of primary graft dysfunction, a known risk factor of BOS. ${ }^{13}$ Two key findings in the present study strongly suggest the role of ET-1 in clinical BO. First, the pretransplant serum ET-1 level was significantly increased in patients who developed BOS. Second, the patients who developed BOS showed persistent post-transplant ET-1 elevation in their serum, BAL, and pulmonary tissue. Third, the serum ET-1 levels correlated with those in the BAL of the lung recipients, indicating that the lung allograft was the main source of circulating ET-1.

The pretransplant serum ET-1 was significantly elevated compared with the post-transplant serum ET-1 in all study patients. One explanation might be that pretransplant ET1 level represents an inflammatory response to the massive pulmonary damage owing to the underlying lung disease. Importantly, our current data revealed that the pretransplant ET-1 is a useful predictor of BOS, independent of acute rejection. Furthermore, patients with elevated pretransplant ET-1 levels were associated with elevated post-transplant ET-1 levels and more acute rejection episodes. This phenomenon could have been because ET-1 contributes to endothelial necrosis, as shown previously in a transplanted tracheal model. The latter response can trigger immune reactions and acute rejection episode. ${ }^{11}$ The acute rejection, in turn, contributes to additional allograft damage and upregulation of ET-1 production. It has also been shown that nonimmunologic factors and cyclosporine treatment could contribute to ET-1 upregulation in lung transplant recipients. ${ }^{20}$ However, the association among ET-1, cyclosporine, and BOS calls for additional studies. Taking together, the repeated immunologic and nonimmunologic insults against the lung graft might result in elevation of pulmonary ET-1 that contributes to BO development.

TBB remains the reference standard diagnostic tool for BO. However, TBB is invasive and can deliver falsenegative results owing to the patchy nature of $\mathrm{BO} .{ }^{15}$ Therefore, a diagnostic biomarker, preferably a serum biomarker, could facilitate the diagnosis of $\mathrm{BO}$ and reduce patient morbidity. We have recently reported that BAL matrix 
metalloproteases could be a diagnostic marker of $\mathrm{BO}^{19}$; however, serum biomarkers are less invasive. The present results have shown that serum ET-1 can serve as an independent and noninvasive serum biomarker for the early prediction of BOS and its monitoring in lung transplant recipients. This assumption calls for randomized prospective studies, which we are planning at our center.

\section{References}

1. Taylor DO, Edwards LB, Boucek MM, Trulock EP, Aurora P, Christie J, et al. Registry of the International Society for Heart and Lung Transplantation: twenty-fourth official adult heart transplant report-2007. J Heart Lung Transplant. 2007;26:769-81.

2. Lama VN. Update in lung transplantation 2008. Am J Respir Crit Care Med. 2009; 179:759-64.

3. Scott AI, Sharples LD, Stewart S. Bronchiolitis obliterans syndrome: risk factors and therapeutic strategies. Drugs. 2005;65:761-71.

4. Lama VN, Murray S, Lonigro RJ, Toews GB, Chang A, Lau C, et al. Course of FEV(1) after onset of bronchiolitis obliterans syndrome in lung transplant recipients. Am J Respir Crit Care Med. 2007;175:1192-8.

5. Burton CM, Iversen M, Carlsen J, Mortensen J, Andersen CB, Steinbrüchel D, et al. Acute cellular rejection is a risk factor for bronchiolitis obliterans syndrome independent of post-transplant baseline FEV1. J Heart Lung Transplant. 2009; 28:888-93.

6. Meloni F, Solari N, Miserere S, Morosini M, Cascina A, Klersy C, et al. Chemokine redundancy in BOS pathogenesis: a possible role also for the $\mathrm{CC}$ chemokines: MIP3-beta, MIP3-alpha, MDC and their specific receptors. Transpl Immunol. 2008; 18:275-80.

7. Jeppsson A, Tazelaar HD, Miller VM, McGregor CG. Distribution of endothelin1 in transplanted human lungs. Transplantation. 1998;66:806-9.

8. Uguccioni M, Pulsatelli L, Grigolo B, Facchini A, Fasano C, Cinti C, et al. Endothelin-1 in idiopathic pulmonary fibrosis. J Clin Pathol. 1995;48:330-4.
9. Fagan KA, McMurtry IF, Rodman DM. Role of endothelin-1 in lung disease. Respir Res. 2001;2:90-101.

10. Shennib H, Serrick C, Saleh D, Adoumie R, Stewart DJ, Giaid A. Alterations in bronchoalveolar lavage and plasma endothelin-1 levels early after lung transplantation. Transplantation. 1995;59:994-8.

11. Tikkanen JM, Koskinen PK, Lemström KB. Role of endogenous endothelin-1 in transplant obliterative airway disease in the rat. Am J Transplant. 2004;4: 713-20.

12. Taghavi S, Abraham D, Riml P, Paulus P, Schäfer R, Klepetko W, et al. Coexpression of endothelin-1 and vascular endothelial growth factor mediates increased vascular permeability in lung grafts before reperfusion. J Heart Lung Transplant. 2002;21:600-3

13. Salama M, Andrukhova O, Hoda MA, Taghavi S, Kelpekto W, Aharinejad S. Concomitant endothelin-1 overexpression in lung transplant donors and recipients predicts primary graft dysfunction. Am J Transplant. 2009;10:628-36.

14. Antus B, Sebe A, Fillinger J, Jeney C, Horvath I. Effects of blockade of the renin angiotensin and endothelin systems on experimental bronchiolitis obliterans. J Heart Lung Transplant. 2006;25:1324-9.

15. Estenne M, Maurer JR, Boehler A, Egan JJ, Frost A, Hertz M, et al. Bronchiolitis obliterans syndrome 2001: an update of the diagnostic criteria. J Heart Lung Transplant. 2002;21:297-310.

16. Aharinejad S, Taghavi S, Klepetko W, Abraham D. Prediction of lung-transplant rejection by hepatocyte growth factor. Lancet. 2004;363:1503-8.

17. Vanaudenaerde BM, De Vleeschauwer SI, Vos R, Meyts I, Bullens DM Reynders V, et al. The role of the IL23/IL17 axis in bronchiolitis obliterans syndrome after lung transplantation. Am J Transplant. 2008;8:1911-20.

18. Scherstén H, Hedner T, McGregor CG, Miller VM, Martensson G, Riise GC et al. Increased levels of endothelin-1 in bronchoalveolar lavage fluid of patients with lung allografts. J Thorac Cardiovasc Surg. 1996;111:253-8.

19. Taghavi S, Krenn K, Jaksch P, Klepetko W, Aharinejad S. Broncho-alveolar lavage matrix metalloproteases as a sensitive measure of bronchiolitis obliterans. Am J Transplant. 2005;5:1548-52.

20. Silverborn M, Ambring A, Nilsson F, Friberg P, Jeppsson A. Blunted vascular response to endothelin-a receptor blockade in cyclosporine-treated lung transplant recipients. J Heart Lung Transplant. 2005;24:665-70. 